\title{
What Is the Impact of the Impact Factor?
}

\section{Kostas Kampourakis ${ }^{1}$}

Published online: 15 August 2018

(C) Springer Nature B.V. 2018

Every year, journal publishers and editors are waiting to find out the new impact factors of journals. Roughly put, this metric stems from a calculation of how many times articles published in a certain journal during a certain number of recent years were cited in other articles during the previous year. In a sense, the impact factor indicates how much articles in a particular journal have been cited. This sounds important. But one might wonder if it is really important. One reason is that there are several other metrics. Another reason is that the impact factor only provides a snapshot of how much the articles published in a particular journal were cited during a particular period. One might thus wonder whether the attention paid to this metric is really deserved.

The 2017 impact factor of Science \& Education is 1.265, having gone up from 0.823 in 2016. This was an impressive increase. But what does this increase really represent? To answer this question, I am going to try to outline what I think brought about this increase. If the causes I am going to identify are really the ones responsible for the increase in the impact factor, then this metric really means something and-as I explain in the end-the impact factor can potentially have a big impact.

Since 2015, when our editorial team took over, we have been consistently presenting the aims, the scope, and the published contents of Science \& Education in the NARST and ESERA conferences. These are the largest (annual and biannual, respectively) science education conferences, attended by more than one thousand participants from all over the world. The means by which the presentation of our journal was made were different in each case, but they were equally effective. On the one hand, the ESERA organizers have been inviting me as the editor-in-chief of the journal to organize symposia with presentations of papers already published in the journal, with the aim to show what kinds of papers we publish. The NARST organizers, on the other hand, have been organizing special sessions about journals and publishing, which have been very interesting. At the same time, I have been proposing symposia at NARST conferences with new papers on topics that fall within the scope of Science \& Education, which gave us the opportunity to show what kinds of papers we would like to publish.

Kostas Kampourakis

Kostas.Kampourakis@unige.ch

1 Section of Biology and IUFE University of Geneva, Geneva, Switzerland 
All in all, these activities have made these large science education communities better aware of the aims, scope, and content of Science \& Education. Thus, more people have started reading, reviewing, and submitting articles to the journal. They all eventually came to realize that Science \& Education is a journal of interest to all of them, which only differs from other science education journals in that it has a special focus: the articles published in our journal are informed by scholarship in history, philosophy, and sociology of science. This is, in our view, an advantage for the work published in Science \& Education, because it allows for a solid theoretical grounding. And this is what makes these articles interesting and useful for everyone in the international science education community.

I believe that the recent increase in the impact factor of Science \& Education is the result of our efforts to make the science education community realize that there is a lot of interesting and useful content in our journal. And now, the increase of the impact factor will likely attract more people to the journal. This is, I believe, the impact of the impact factor. Whether or not this metric can accurately represent the quality of the contents of the journal, it is a metric that most people look at. It makes the journal more attractive to authors and readers. If this recent increase will indeed bring more readers, reviewers, and authors to Science \& Education, this remains to be seen. Our responsibility is to continue to have high-quality articles published in our journal and make the science education community aware of them.

As I am writing these lines, there are calls for papers on the following: (i) practical aspects in teaching nature of science; (ii) scientific practices, epistemic aims, and learning progressions, and (iii) genetics and identity. We welcome submissions on these topics and, of course, on any other topic within the scope of Science \& Education.

\section{Compliance with Ethical Standards}

Conflict of Interest The author declares no conflict of interest. 